\title{
Association between Anxiety and Depression with Irritable Bowel Syndrome in Mosul
}

\author{
Dr. Firas Husam Ali ${ }^{a}$, Prof. Dr. Samim A. Al - Dabbagh ${ }^{\text {b }}$ \\ ${ }^{a}$ Al - Quds family medicine and training center, DOH Ninavah, Mosul, Iraq, ${ }^{b}$ Department of Family and Community \\ Medicine, University of Duhok, Duhok, Iraq. Correspondence: Firas Husam Ali. firashusam@gmail.com.
}

(Ann Coll Med Mosul 2019; 41 (1):63-68).

Received: 21 ${ }^{\text {st }}$ Oct. 2018; Accepted: 24 ${ }^{\text {th }}$ Mar. 2019.

\section{ABSTRACT}

Background: Irritable Bowel Syndrome (IBS) is the most common disorder seen in gastroenterology practice. It is also a large component of primary care practices.

Aim: To determine the association between anxiety and depression and Irritable bowel syndrome.

Methods: A case - control study design was adopted to achieve the aim of the present study. This study was conducted in Mosul city and sample was taken from the inward and outward patient department of AlZahrawi, Ibn-Seena teaching hospitals and Al-Salaam general hospital. The actual period of data collection has been extended between $\left(20^{\text {th }}\right.$ of December $2006-31^{\text {st }}$ of July 2007). A total of 150 cases diagnosed to have IBS by Rome II criteria. Another 150 control group was diagnosed as Rome II negative of apparently healthy individuals which were relatives of patients other than IBS matched according to age (+ 5 years) and sex with cases. A specially designed questionnaire form has been used to help in diagnosing IBS cases according to Rome II criteria. To assess anxiety in cases and controls, ICD- 10 checklist was used and its variables have been planned to be assessed as risk factors and For the diagnosis of depression the international diagnostic checklist for ICD - 10 ( IDCL) has been used.

A questionnaire form filling is through direct interviewing with cases and controls. Chi - square test for contingency tables was used to test for the presence or absence of statistical association or differences between cases and controls, $Z$ - test for the differences between two proportions was used. During statistical analysis $\mathrm{P}$ - value of $<0.05$ was considered significant.

Results: present study shows that the majority of cases (93.3\%) were below 55 years. Female to male ratio among cases was 1.9:1. The majority of cases had a mild symptom. Anxiety was found to be a significant risk factor in the development of IBS, this study showed that $64.8 \%$ were females with anxiety in comparison to $35.2 \%$ males and this study showed that those with depression had a very highly significant risk to develop IBS $(\mathrm{OR}=4.50)$ and those with both anxiety and depression have 5 times risk to develop IBS in comparison to those with anxiety or depression or none (OR=5.21, $\mathrm{P}<0.001)$.

Conclusion: In this study, IBS patients appeared to have a significant association with anxiety, depression and these factors maybe played a causative role in the development of IBS.

Keywords: Irritable bowel syndrome, anxiety, depression.

$$
\begin{aligned}
& \text { العلاقة بين القلق والكآبة مع متلازمة الأمعاء المستثارة في الموصل }
\end{aligned}
$$

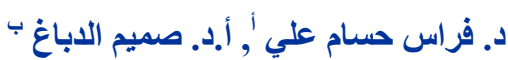

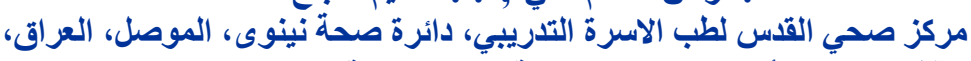

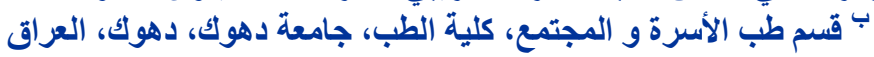

الخلفية: متلازمة القولون العصبي (IBS) هو إضطر اب وظيفي معوي شائع ينظر إليه في ممارسات الجهاز الهضمي ومكون

$$
\text { كبير من ممارسات الرعاية الأولية. }
$$


الهُف: الهذف من هذه الدر اسة هو تحديد العلاقة بين القلق ومتلازمة القولون العصبي.

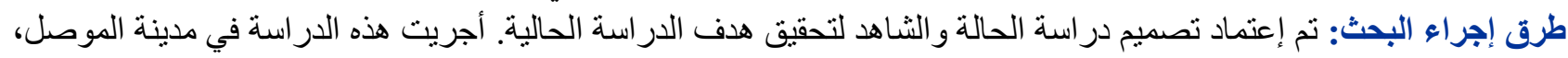

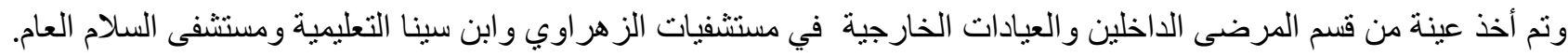

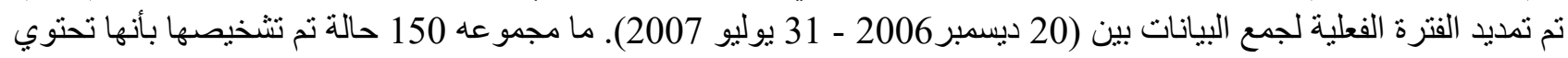

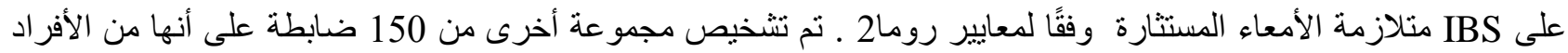

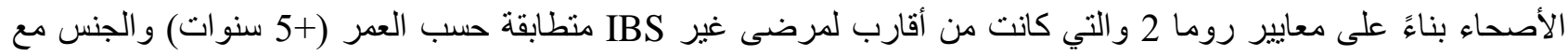

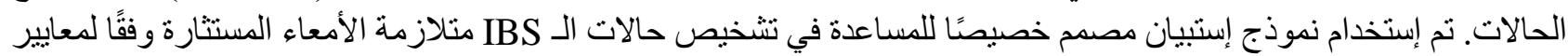

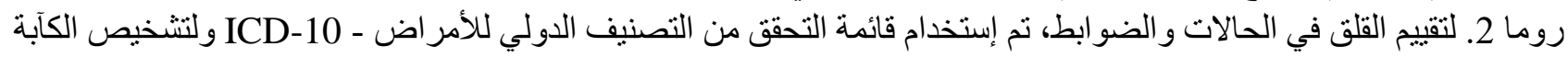

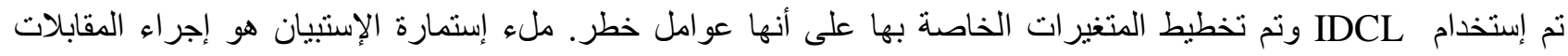

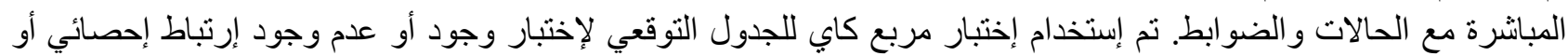

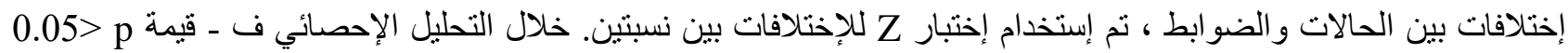
أعنبرت هامة. النتائج: أظهرت الدر اسة الحالية أن غالبية الحالات (93.3 \%) كانت أقل من 55 عاما. نسبة الإناث إلى الذكور بين الحالات كانت

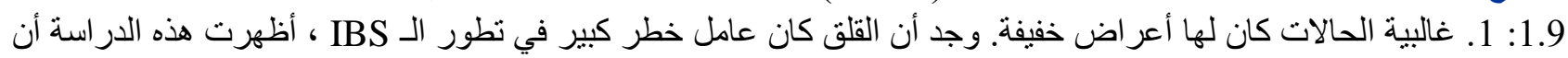

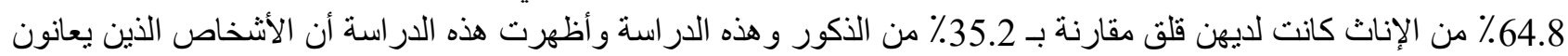

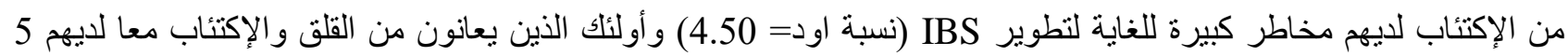

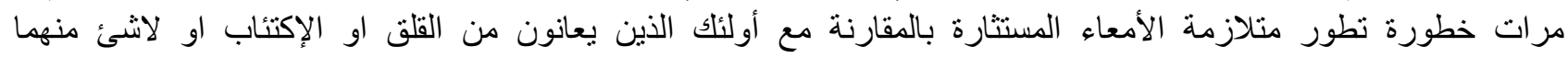
. $(\mathrm{OR}=5.21, \mathrm{P}<0.001)$

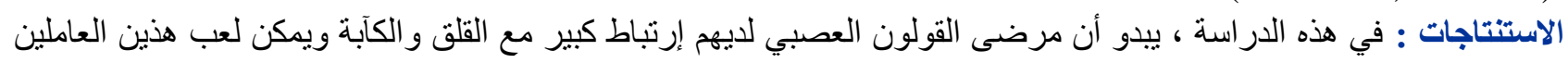

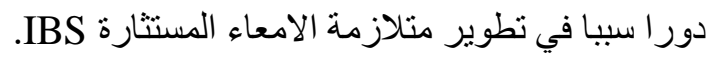

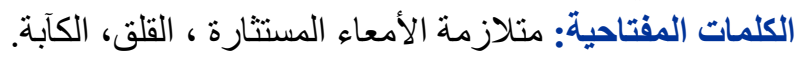

\section{INTRODUCTION}

rritable Bowel Syndrome (IBS) is the most common disorder seen in gastroenterology practice. It is also a large component of primary care practices. ${ }^{1}$ It's a chronic, episodic disease characterized by abdominal pain or discomfort without an identifiable organic cause, altered bowel habit, and other prominent symptoms such as bloating, flatulence, urgency, diarrhea or constipation and feeling of incomplete evacuation ${ }^{2}$. It is typically categorized into 3 subtypes based on the primary bowel habit which is IBS diarrhea (IBS-D), IBS constipation (IBS-C) and IBS with alternating diarrhea and constipation (IBS-A) ${ }^{3,4}$.

\section{Risk factors of IBS}

Irritable bowel syndrome, like many other poorly understood disorders, is viewed as a multifactorial disease, It's symptoms and clinical outcome may depend on the interaction of several factors which include: ${ }^{5,6}$

- Psychological factors.

- Dietary factors.
- Menstrual cycle.

- Post infections.

- Abdominal and pelvic surgery.

- Genetics and familial aggregations $s^{5,6}$.

- Psychological factors.

Psychosocial and social diseases are considered the most important factor in terms of who complaining from IBS and how sever it becomes. One of the psychological factors is the stress which is widely believed to have a major role in functional gastrointestinal disorders (FGID) especially IBS, by either precipitating or exacerbating of its symptoms. At referral centers, as many as $60 \%$ of patients with IBS have psychiatric symptoms, including depression, anxiety, somatization, and personality disorders ${ }^{7}$.

\section{Pathophysiology of IBS ${ }^{8}$}

It include: Altered gut motility, Visceral hypersensitivity, Brain- gut interaction, Neurotransmitter imbalance, Inflammation. 
Aim of the study

The aim of the present study is to determine the association between psychosocial factors (anxiety and depression) and irritable bowel syndrome (IBS) in Mosul.

\section{PATIENTS AND METHODS}

Study setting: This study was conducted in Mosul city, sample was taken from the inward and outward patient department of the following hospitals (Al-Salaam general hospital, Ibn-Seena and Al-Zahrawi teaching hospitals).

Study design: A case - control study design was adopted to achieve the aim. To examine the possible relation of an exposure to a certain risk factors, a group of people with the disease (case) and group of people without disease (control) were be identified ${ }^{9}$. The cases defined as an Adult of both sexes diagnosed clinically to have IBS according to Rome II criteria by a specialist physician. The patient was diagnosed to have IBS if he was matched with Rome II criteria as shown in Table (1) in addition to limited investigations for patients who may have other disorders simulating IBS.

Plus the absence of the following exclusion criteria" Alarm features "10,11:

1. Fever.

2. Weight loss.

3. Bleeding per rectum.

4. Anemia.

5. Family history of colonic cancer or IBD.

6. Recent use of antibiotics.

7. New or recent onset in patient older than 50 years.

8. Nocturnal symptoms.

9. Palpable, abdominal or rectal mass. ${ }^{10,11}$

The control should be a Presumably normal adult person from both sexes, all controls have been encountered from the relatives accompanying patients (other than IBS patients) who attend the outpatient clinic or admitted to hospital and diagnosed by specialist physician as Rome II negative persons matched for age $( \pm 5$ years) and sex with cases.

\section{Period of the study}

The actual period of data collection has been extended between $\left(20^{\text {th }}\right.$ of December $2006-31^{\text {st }}$ of March 2007), during this period 95 cases and 95 controls were collected. This period was then extended for another 2 months to complete the sample of 150 cases and 150 controls.

Tools of data collection

A detailed questionnaire form was prepared to record all relevant information related to cases and controls in the sample, this questionnaire form consist of 2 parts:

\section{Questionnaire form A}

Which is used for the diagnosis of IBS by specialist physician by using Rome II criteria.

\section{Questionnaire form B}

Which is filled by the researcher through interviewing with cases and controls which include:

A. General information

These information include name, number of the participants (case / control), age, sex, religious, marital state, occupation, education and residence.

B. Diagnosis of anxiety

Specific questions have been used to diagnose anxiety; here the diagnostic checklist is used to diagnose anxiety depending on the Tenth Revision of the International Statistical Classification of Diseases and Related Health Problems (ICD-10) checklist which is approved by World Health Organization (WHO) ${ }^{12}$.

C. Diagnosis of depression

For the diagnosis of depression the IDCL has been used $^{13}$.

Computer feeding and statistical analysis were carried out using Pentium IV computer with SPSS and Minitab programs.

Chi - square $\left(\chi^{2}\right)$ test for contingency tables was used to test for the presence or absence of statistical association or differences between cases and controls, Z-test for the differences between two proportions was also used. During statistical analysis $\mathrm{P}$-value of $\leq 0.05$ was considered significant ${ }^{14}$.

\section{RESULTS}

Characteristics of the study populations

Table (1) demonstrates characteristics of the study population related to the distribution of age, sex, religion and residence. The sample was grouped into five age strata that covered the study population ages. The mean ages of cases was slightly higher than that of controls $40.88 \pm 11.13$ 
and $39.35 \pm 10.99$. The same table reveals that $32 \%$ of cases were located in the age group (36-45), $28 \%$ were in the age group (46-55) and $22 \%$ were in the age group (26-35).

The majority of cases were females $65.3 \%$ and $34.7 \%$ were male with female: male ratio about 1.9:1. Most of the cases and controls were from the urban area $89 \%$ and about $11 \%$ were from the rural area.

Case - control analysis of the risk factors

\section{Anxiety}

Table (2) clarifies that $60.7 \%$ of cases had anxiety in comparison to $26 \%$ of controls with a very highly significant difference between two groups. Odds ratio reveals that those with anxiety had 4 times risk to develop IBS than those without $(\mathrm{OR}=4.40$, $\mathrm{P}<0.001$ ).

\section{Depression}

Table (3) demonstrates that $53.3 \%$ of cases in comparison to $20 \%$ of controls had depression which shows that those with this variable had a very highly significant risk to develop IBS ( $\mathrm{OR}=4.50, \mathrm{P}<0.001)$.

\section{Anxiety and depression}

Table (4) clarifies the association between IBS and both (anxiety and depression). It indicates that the difference between cases and controls according to this variable was very highly significant with 5 times risk to develop IBS among those with anxiety and depression in comparison to those with anxiety, depression or none (OR=5.21, $\mathrm{P}<0.001)$.

Table 1: Characteristics of the study population.

\begin{tabular}{|c|c|c|c|c|c|c|c|c|}
\hline \multirow{2}{*}{ Age (year) } & \multicolumn{3}{|c|}{ Cases } & \multicolumn{3}{|c|}{ Control } & \multicolumn{2}{|c|}{ Total } \\
\hline & No. & $\%$ & Mean \pm SD & No. & $\%$ & Mean \pm SD & No. & $\%$ \\
\hline $16-25$ & 17 & 11.3 & \multirow{7}{*}{$40.88 \pm 11.13$} & 17 & 11.3 & \multirow{6}{*}{$39.35 \pm 10.09$} & 34 & 11.3 \\
\hline $26-35$ & 33 & 22.0 & & 46 & 30.7 & & 79 & 26.3 \\
\hline $36-45$ & 48 & 32.0 & & 47 & 31.3 & & 95 & 31.8 \\
\hline $46-55$ & 42 & 28.0 & & 28 & 18.7 & & 70 & 23.3 \\
\hline 56_and more & 10 & 6.7 & & 12 & 8.0 & & 22 & 7.3 \\
\hline Total & 150 & 100 & & 150 & 100 & & 300 & 100 \\
\hline \multicolumn{8}{|l|}{ Gender } & \\
\hline Female & 98 & 65.3 & & 99 & 66.0 & & 197 & 65.7 \\
\hline Male & 52 & 34.7 & & 51 & 34.0 & & 103 & 34.3 \\
\hline Total & 150 & 100 & & 150 & 100 & & 300 & 100 \\
\hline \multicolumn{9}{|l|}{ Residence } \\
\hline Urban & 123 & 82.0 & & 144 & 96.0 & & 267 & 89.0 \\
\hline Rural & 27 & 18.0 & & 6 & 4.0 & & 33 & 11.0 \\
\hline Total & 150 & 100 & & 150 & 100 & & 300 & 100 \\
\hline
\end{tabular}

Table 2: Distribution of cases and controls according to anxiety.

\begin{tabular}{lcccccccc}
\hline \multirow{2}{*}{ Anxiety } & \multicolumn{2}{c}{ Cases } & \multicolumn{2}{c}{ Control } & \multirow{2}{*}{ OR } & \multirow{2}{*}{$95 \%$ C.I. } & \multirow{2}{*}{ p-value } \\
\cline { 2 - 5 } & No. & $\%$ & No. & $\%$ & & & \multirow{2}{*}{$2.70-7.20$} & $<0.001$ \\
\hline Present & 91 & 60.7 & 39 & 26.0 & \multirow{2}{*}{4.40} & & \\
Absent & 59 & 39.3 & 111 & 74.0 & & & \\
Total & 150 & 100 & 150 & 100 & & & \\
\hline
\end{tabular}

Table 3: Distribution of cases and controls according to depression.

\begin{tabular}{lccccccc}
\multicolumn{1}{r}{ Depression } & \multicolumn{2}{c}{ Cases } & \multicolumn{2}{c}{ Control } & \multirow{2}{*}{ OR } & \multirow{2}{*}{ 95\% C.I. } & p-value \\
\cline { 1 - 5 } & No. & $\%$ & No. & $\%$ & & & \multirow{2}{*}{0.001} \\
Present & 80 & 53.3 & 30 & 20.0 & \multirow{2}{*}{4.50} & $2.70-7.50$ & $<0.00$ \\
\hline Absent & 70 & 46.7 & 120 & 80.0 & & & \\
\hline Total & 150 & 100 & 150 & 100 & & & \\
\hline
\end{tabular}


Table 4: Distribution of cases and controls according to anxiety and depression.

\begin{tabular}{|c|c|c|c|c|c|c|c|}
\hline \multirow{2}{*}{ Anxiety and depression } & \multicolumn{2}{|c|}{ Cases } & \multicolumn{2}{|c|}{ Control } & \multirow{2}{*}{ OR } & \multirow{2}{*}{ 95\% C.I. } & \multirow{2}{*}{ p-value } \\
\hline & No. & $\%$ & No. & $\%$ & & & \\
\hline Anxiety and dep. & 55 & 36.7 & 15 & 10.0 & \multirow{3}{*}{5.21} & \multirow{3}{*}{$2.78-9.77$} & \multirow{3}{*}{$<0.001$} \\
\hline Anxiety or dep. or none & 95 & 63.3 & 135 & 90.0 & & & \\
\hline Total & 150 & 100 & 150 & 100 & & & \\
\hline
\end{tabular}

\section{DISCUSSION}

Irritable bowel syndrome is widespread in all societies and socio-economic groups. Although this disease is not a life threatening, patients with IBS are seriously affected in their everyday life. In the present study the majority of cases were below 55 years of age and there is some cases above 50 years of age in this study but they does not have their first attack above 50 years of age. This is in agreement with similar conducted studies ${ }^{15}$. No sex difference was observed between cases and controls this is because of the matching conducted in this study, while, female to male ratio among cases in the same study was 1.9:1 this finding was in consistence with that stated by other study in Saudi and nearly mimic other studies ${ }^{16}$.

The psychopathology seen in patients with functional gastrointestinal disorders is of two types: one is a characteristic of illness itself and the other leads the individuals to consult a physician. The psychological problems found in many of the individuals with psychosomatic disorders need to be assessed to determine whether they should be regarded as correlates of the disorder itself, as a results of the disorder, or as a result of selection effect of patients who have chosen to consult a physician ${ }^{17,18}$.

There is growing evidence that psychological factors including certain forms of stress are at least partially responsible for maintenance and exacerbation of IBS symptoms ${ }^{19}$.

Assessment of psychology is difficult and might be inaccurate in some situations. The present study chose the Tenth Revision of the International Statistical Classification of Diseases and Related Health Problems (ICD-10) check list which is approved by World Health Organization (WHO), assessment of psychological status by (ICD-10) is thought to generate a database useful in both routine clinical care and research ${ }^{13}$.

Psychological problems might have a significant impact in Iraq due to the effect of wars, sanction on its community. This assessment revealed that there was a significant association between anxiety and IBS $(p<0.001)$, those with anxiety were associated with an elevated risk of IBS $(\mathrm{OR}=4.40)$. This finding was in agreement with other studies conducted by Spiller ${ }^{20}$.

On the other hand, the present study demonstrated that there was a significant association $(p<0.001)$ between depression and IBS. This variable could played a causative role in the development of IBS (OR=4.50), this finding was consistent with that conducted by another study ${ }^{21}$.

It is worth mentioning that for IBS the odds ratio of anxiety and depression were 4.40 and 4.50 respectively this was increased by using combined anxiety and depression to 5.21 with a significant association between both groups by using combined variables ${ }^{22}$ but one of the important thing is that the anxiety and depression could be an outcome of IBS itself.

\section{CONCLUSIONS}

The following conclusions were obtained from the discussion of the results of this study:

1. The majority of IBS cases were below the age of 55 years with female to male ratio among the cases were 1.9:1.

2. In this study, IBS patients appeared to have a significant association with psychological factors (anxiety and depression) and these factors may be played a causative role in the development of IBS.

3. Females were experienced more psychological factors than male, although this association was not statistically significant.

\section{REFERENCES}

1. Olden, K. Diagnosis of irritable bowel syndrome. Gastroenterology. 2002; 122: 1701-1714.

2. Neda F, Mehdi G, Bijan M, Nosrotollah N, Farbod F. Evaluation of psychological aspects among subtypes of 
irritable bowel syndrome. Ind J. of Psy Medicine 2012; 34 (2): 144-148.

3. Bueno L. Gastrointestinal pharmacology: irritable bowel syndrome. Curr Opin in Pharmacology. 2005; 5(6): 583-588.

4. Liming Z, Dan H, Lili S, Liexin L, Tao X, Min C, et al. Intestinal symptoms and psychological factors jointly affect quality of life of patients with irritable bowel syndrome with diarrhea. Health and Quality of Life Outcomes. 2015;13: 49.

5. Kennedy $T$, Rubin $G$, Jones R. Clinical evidence concise: irritable bowel syndrome. Am Fam Physician. 2005; 71(3): 421.

6. Pantoflickova D, Michetti D, Fried M, Beglinger C, Blum A. Meta - analysis: the treatment of irritable bowel syndrome. Aliment Pharmacol Ther 2004; 20(11): 12531269.

7. Creed F, Ratcliffe J, Fernandes L, Palmer S, Rigby C, Tomenson B, Guthrie E. Outcome in sever irritable bowel syndrome with and without accompanying depression, panic and neurasthenic disorders. 2005.

8. Delvaux M. Role of visceral sensitivity in the pathophysiology of irritable bowel syndrome. Gut 2002;51(1):167-171.

9. Gordis L. Epidemiology Philadelphia WR - Saunders company. USA 1996: 124-140.

10. Hatlebakk J, Hatlebakk M. Best Practice and Research Clinical Gastroenterology 2004;18(4):735-746. 11. Al-Layla D. Rome II criteria in the diagnosis of irritable bowel syndrome. Ann Coll Med Mosul 2002; 28(2):100-104.

12. Oh Young Lee, Erman A. Mayer, Max Schmulson, Lin Chang L, Bruce Naliboff. Gender - related differences in irritable bowel syndrome symptoms. Am J Gastroenterol 2001;96(7):2184-2193.
13. Janca A, Hiller W. ICD - 10 - Checklists - A tool for clinician's use of the ICD - 10 classification of mental and behavioral disorders. Comprehensive Psychiatry. 1996; 37(3): 180-187.

14. Deary I, Fowkes F, Donnan P, Housley E. Hostile personality and risk of peripheral arterial disease in the general population. Psychsomatic Medicine 1994; 56: 197-202.

15. Malagelada J. A symptom based approach to make a positive diagnosis of irritable bowel syndrome with constipation. Int J of Clinical Practice. 2006 60(1): 57-63. 16. Heitkemper $M$, Jarrett $M$. Overlapping conditions in women with irritable bowel syndrome. Urol Nurs. 2005; 25(1): 25-31.

17. Solmaz M, Karu KI, Sayar K. Psychological factors in the irritable bowel syndrome. Eur J Med Res 2003; 8(12): 549-556.

18. Sykes M, Blanchard E, Lackner J, Keefer L, Krasner S. Psychopathology in irritable bowel syndrome: support for a psychophysiological model. Journal of Behavioral Medicine 2003; 26(4): 361-372.

19. Lackner J, Quigley B. Pain catastrophizing mediates the relationship between worry and pain suffering in patients with irritable bowel syndrome. Beh Res and Therapy. 2005; 43(7): 943-957.

20. Wilhelmsen I. The role of psychosocial factors in gastrointestinal disorders. Gut 2000; 47: 73-75.

21. Smith G. Effect of nurse - led gut - hypnotherapy upon health - related quality of life in patients with irritable bowel syndrome. J Clin Nurs. 2006; 15(6): 678684.

22. Collins S. Stress and the gastrointestinal tract IV. Mechanisms and clinical relevance. Am J Physiol Gastrointestinal Liver Physiol 2001 ;280: 315-318. 